\title{
Evidence for the transmission of Salmonella from reptiles to children in Germany, July 2010 to October 2011
}

M Pees (pees@vmf.uni-leipzig.de) ${ }^{1}$, W Rabsch ${ }^{2}$, B Plenz ${ }^{1}$, A Fruth ${ }^{2}$, R Prager ${ }^{2}$, S Simon ${ }^{2}$, V Schmidt ${ }^{1}$, S Münch ${ }^{2}$, P G Braun ${ }^{3}$

1. Clinic for Birds and Reptiles, University of Leipzig, An den Tierkliniken, Leipzig, Germany

2. National Reference Centre for Salmonella and other bacterial Enterics, Robert Koch Institute, Wernigerode, Germany

3. Institute of Food Hygiene, An den Tierkliniken, Leipzig, Germany

Citation style for this article:

Pees M, Rabsch W, Plenz B, Fruth A, Prager R, Simon S, Schmidt V, Münch S, Braun PG. Evidence for the transmission of Salmonella from reptiles to children in

Germany, July 2010 to October 2011. Euro Surveill. 2013;18(46):pii=20634. Available online: http://www.eurosurveillance.org/ViewArticle.aspx?Articleld=20634

This study examines the Salmonella status in reptiles kept in households with children suffering from gastroenteritis due to an exotic Salmonella serovar, to obtain information on possible transmission paths. A number of affected households $(\mathrm{n}=79)$ were contacted, and almost half (34/79) comprised at least one reptile in the home. Of the households, 19 were further studied, whereby a total of 36 reptiles were investigated. Samples were taken from the reptiles including the oral cavity, the cloaca, the skin and, in the case of lizards, the stomach, and isolation of Salmonella strains was performed using repeated enrichment and typing. Where the Salmonella serovars of the infected child and the reptile were identical, typing was followed by pulsed-field gel electrophoresis (PFGE). Bearded dragons (Pogona vitticeps) constituted 19 of 36 examined reptiles. Altogether 319 Salmonella isolates were investigated and 24 different serovars identified in the reptiles. In 15 of 19 households, an identical serovar to the human case was confirmed in at least one reptile (including 16 of all 19 bearded dragons examined). The results demonstrate that reptiles and especially bearded dragons shed various Salmonella serovars including those isolated from infected children in the respective households. Hygiene protocols and parents' education are therefore highly necessary to reduce the risk of transmission. From a terminological point of view, we propose to call such infections 'ReptileExotic-Pet-Associated-Salmonellosis' (REPAS).

\section{Introduction}

According to Thomas et al. [1] the potential of captive and wild animals to transmit salmonellae to humans should not be underestimated, and epidemiological studies on sources of human salmonellosis should simultaneously investigate both the human cases and the wild and domestic animals in contact with them. A study in 1997 from Canada also estimated that three to five per cent of human Salmonella cases were associated with exposure to exotic pets (including reptiles, sugar gliders, and hedgehogs) and involved a great variety of Salmonella serovars with for example $S$. Stanley, S. Poona, S. Jangwani, S. Pomona, S. subsp. IV 48:g,z51:- (former S. Marina) [2].

Numerous reports exist on the prevalence of Salmonella enterica in captive reptiles, with recent publications demonstrating a higher prevalence in lizards (up to $76 \%$ ) compared to tortoises and turtles [3,4]. Geue and Löschner [5] showed that reptile collections with purchased animals had a significantly higher prevalence of Salmonella than collections from pure breeders. Furthermore, animals from pet shops were more frequently affected (89\%) than wild caught animals (59\%).

Beside the reptiles per se, the reptile feed, in the form of rodents, can also cause infections in humans. In England, a S. Typhimurium definite phage-type was identified as a source of salmonellosis in humans with a strong association to those keeping reptiles, and was also confirmed in frozen feeding-mice originating from a specific rodent breeding facility [6]. In a further outbreak of $S$. Typhimurium related to snakes in the United States (US), pulsed-field gel electrophoresis (PFGE)patterns identical to the human isolates were confirmed for isolates from mice used to feed the snakes as well as the snakes and the environment [7].

Among reptiles, turtles have been reported to be the most common source of Salmonella in the 1970s [8]. However, later studies and surveys indicate that other reptile species, especially lizards, may play a more important role [9-13]. Measures targeted at the prevention of turtle-associated salmonellosis in the US and Canada in the 1970 s temporary helped to reduce its occurrence, however reptile-associated salmonellosis is suspected to be a resurgent problem and estimated to cause three to $11 \%$ of all human salmonellosis cases in these countries $[2,14,15]$. 
Most reports of reptile-associated salmonellosis concern babies (less than one year of age) and young children (up to six years-old). However, adults can be affected, especially immunocompromised hosts, and patients with impaired gastric acid production [16]. Fatal outcomes following reptile-associated salmonellosis (RAS) in babies have been observed [17,18]. In Germany, a recent study [19] reported an increasing number of salmonellosis related to reptiles, with most patients being less than one year-old. The aim of this study was therefore to obtain data on possible links between captive reptiles and salmonellosis in children by examining both the children with salmonellosis and all reptiles kept in the respective households.

\section{Methods}

The study was conducted from July 2010 to October 2011. Within this period, the National Reference Centre (NRC) for Salmonella and other Bacterial Enterics at the Robert Koch Institute (Wernigerode, Germany) examined samples from 206 households with salmonellosis in children not older than three years. Of the Salmonella isolates, $65 \%(134 / 206)$ did not belong to $S$. Typhimurium and $S$. Enteritidis and were therefore of interest for this study. The responsible federal health institutes were asked to contact these households. A total of 79 parents, corresponding to 79 households, were successfully contacted by mail and asked about the presence of reptiles in the respective households. Thirty-five of 79 parents confirmed having reptiles and were contacted by phone to attend this study. As inclusion criteria for participation, parents had to agree that all reptiles in the respective household could be sampled and their health status assessed, and the time period between detection of clinical salmonellosis in the child and the sampling of the reptiles was not more than three weeks.

Species and health status of the reptiles were assessed and sampling was conducted following established guidelines using sterile cotton swabs (Heinz Herenz, Hamburg, Germany). Swabs were taken from the oral cavity, the cloaca, and the skin on the ventral region of the reptile. For lizards, an additional swab sample was taken from the stomach. Bacterial isolation and identification were conducted with repeated enrichment and examination of several colonies in each sample, in order to find as many different Salmonella serovars as possible: All samples were immediately placed into a tube containing Rappaport-Vassiliadis (RV) medium (Oxoid, Wesel, Germany). This medium was cultured aerobically for $24 \mathrm{~h}$ at $39^{\circ} \mathrm{C}$. A sample was then plated onto sheep blood agar as well as XLT-4Agar (Oxoid, Wesel, Germany) and cultured aerobically for further $24 \mathrm{~h}$ at $39^{\circ} \mathrm{C}$. From the RV bouillon culture, $1 \mathrm{ml}$ was transferred to a new tube containing RV, and enrichment as well as culture was repeated. This procedure was repeated again, so that in total isolation of Salmonella spp. was attempted from three enrichment cycles. From Salmonella-suspicious colonies, at least five different colonies were subcultured on Brilliant
Green agar (Sifin, Berlin, Germany) for confirmatory testing with biochemical methods. Confirmed colonies were agglutinated against Salmonella surface antigens (sera from Sifin, Berlin, Germany) and all strains were typed at the NRC according to the White-Kauffmann-Le Minor scheme [20].

The isolates of identical serovars confirmed in the infected child and the reptile were compared using PFGE. PFGE was carried out according to the standardised protocol for subtyping Salmonella [21]. 40 strains (human and animal) were investigated by PFGE. In case of minor pattern differences between the reptile and the human isolate of the respective household, the PFGE was repeated. Interpretation of the PFGE results followed recent recommendations from the literature [22-24]: Identical PFGE patterns were considered to represent the same epidemiological type. Depending on the time the outbreak has been going on and if person to person spread is the prominent feature, two to three [23] or up to four differences [22] in PFGE restriction fragment pattern are considered to be the result of a single genetic event, and isolates can be designated as 'subpatterns' or related patterns. Given the maximum time period (several weeks between initial infection of the child and final sampling of the reptile) for this study, more than two differences were considered to represent an epidemiologically-significant difference.

\section{Results}

Nineteen households met the inclusion criteria for participation in the study and reptiles were thus investigated. Altogether, 36 reptiles were kept in the households and included in this study (per household between 1 and 7, on average 1.9). Details are listed in Table 1 . In these 19 households, Salmonella serovars isolated from the children belonged mainly to subspecies I (12 households), but also subspecies II (1 household), subspecies IIIa (1 household), subspecies IIIb (2 households) and subspecies IV (3 households) (Table 1). One $S$. Newport strain $(6,8: \mathrm{e}, \mathrm{h}: 1,2: z 67$, d-tartrate-, malonate+) was investigated in Paris (Institut Pasteur) because of its unusual biochemical properties. The strain exhibited two atypical characteristics: D-tartrate negative and malonate positive. The ' $e, h$ ' and the ' 1,2 ' flagellar phases have been confirmed by flic and fljB sequencing. The multilocus sequence typing (MLST) profile (ST118) was identical to those of serovar Newport lineage II [25].

Investigated households were spread well over Germany, including nine (of 16 possible) federal states (Bavaria, Baden-Württemberg, Berlin, North RhineWestphalia, Rhineland-Palatinate, Saxony, SaxonyAnhalt, Schleswig-Holstein, Thuringia). From the investigated households, all children except one were less than 15 months of age, most (11/19) were less than six months. All children showed clinical symptoms of gastroenteritis including fever, with some being critically ill. Except for three serovars (S. Eastbourne 9,12:e,h:1,5; S. subspec. IV 44:z4,z23:-; S. Monschaui 

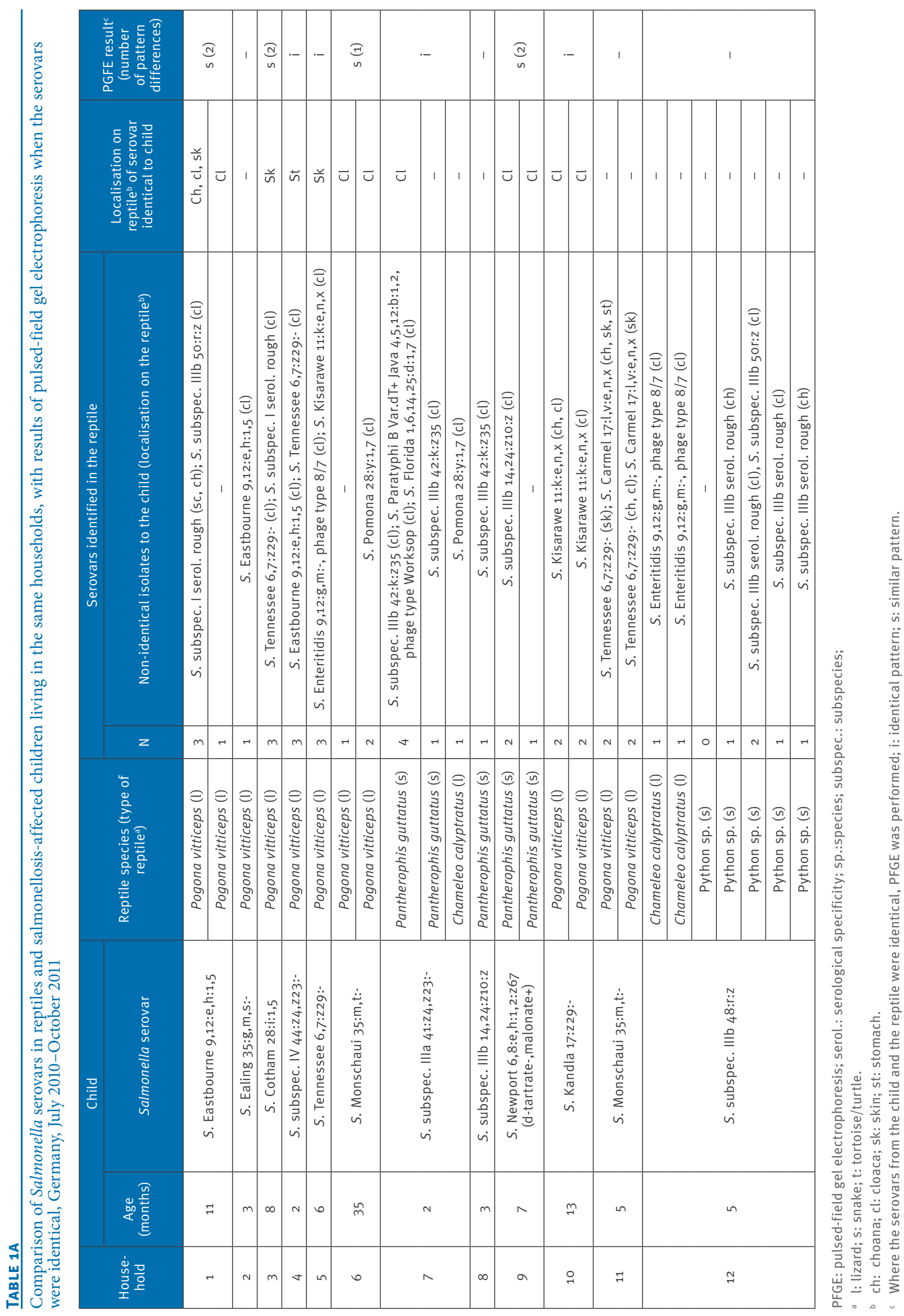


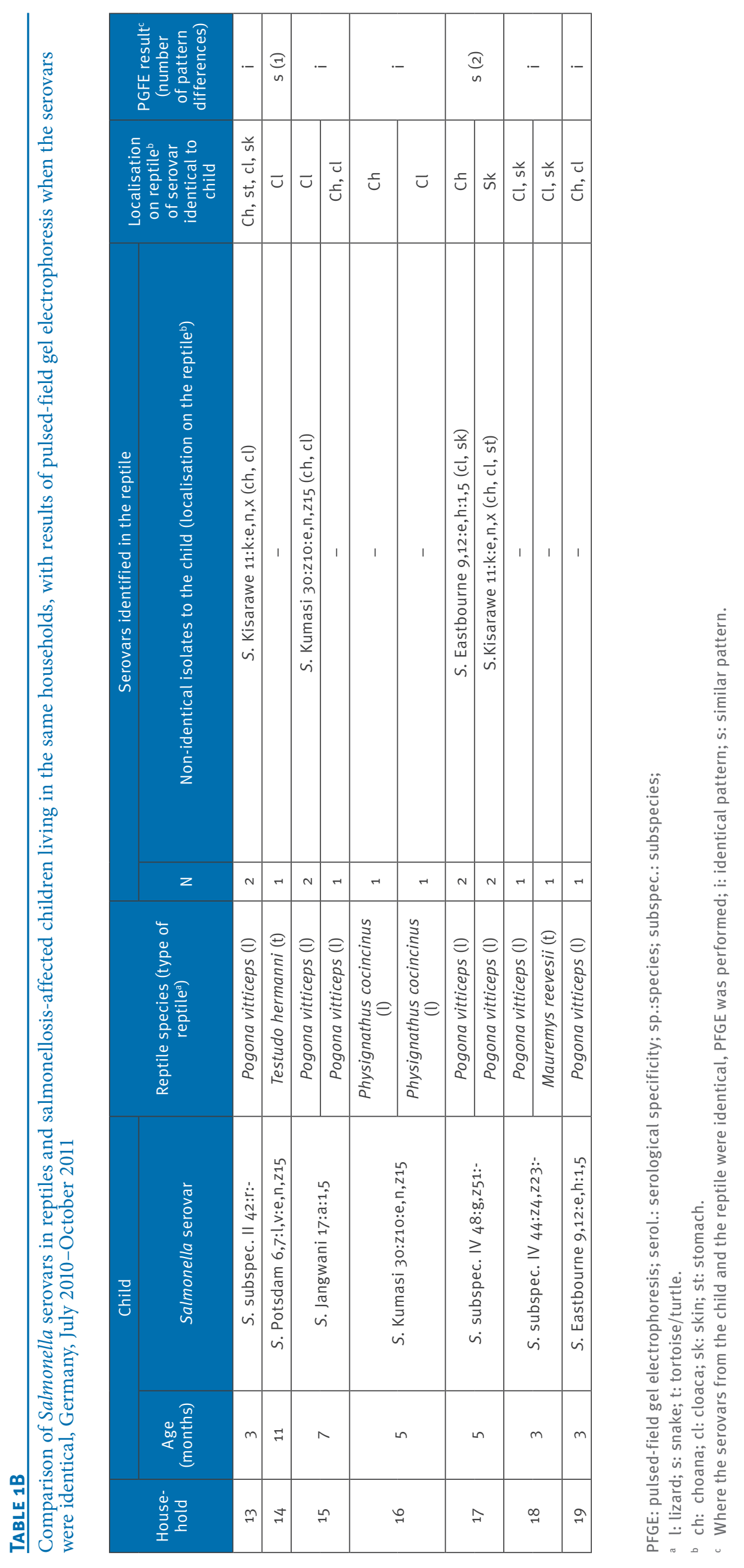


Number of reptile species and representative animals $(n=36)$ in households $(n=19)$ with 'Reptile-Exotic-Pet-AssociatedSalmonellosis' (REPAS) human cases and reptile distribution among the households, Germany, July $2010-$ October 2011

\begin{tabular}{|c|c|c|c|c|}
\hline \multirow[t]{2}{*}{ Reptile species } & \multirow[t]{2}{*}{ Number of animals } & \multirow{2}{*}{$\begin{array}{l}\text { Number of } \\
\text { households } \\
\text { with this } \\
\text { species }\end{array}$} & \multicolumn{2}{|c|}{$\begin{array}{l}\text { Identical serovars found } \\
\text { in the salmonellosis-affected child } \\
\text { and the reptile }\end{array}$} \\
\hline & & & Number of households & Number of animals \\
\hline $\begin{array}{l}\text { Bearded dragon } \\
\text { (Pogona vitticeps) }\end{array}$ & 19 & 13 & 11 & 16 \\
\hline $\begin{array}{l}\text { Corn snake } \\
\text { (Pantherophis guttatus) }\end{array}$ & 5 & 3 & 2 & 3 \\
\hline Other snakes & 5 & 1 & 0 & 0 \\
\hline Chameleon spp. & 3 & 2 & 0 & 0 \\
\hline Chinese water dragon (Physignathus cocincinus) & 2 & 1 & 1 & 2 \\
\hline Chinese pond turtle (Mauremys reevesii) & 1 & 1 & 1 & 1 \\
\hline Hermann's tortoise (Testudo hermanni) & 1 & 1 & 1 & 1 \\
\hline Total & 36 & $19^{\mathrm{a}}$ & $15^{\mathrm{a}}$ & 23 \\
\hline
\end{tabular}

Spp.: species.

a The total does not equate the sum of the numerical values in the remaining rows of the column because a given household could comprise more than one reptile species.

$35: m, t:-)$ found to have caused infections of two children each, the serovars isolated from the children differed from each other.

A total of 319 Salmonella isolates were investigated and 24 different serovars were identified in the reptiles. The number of serovars within individual reptiles varied between one and four. Only from one snake was no Salmonella isolated. In ten reptiles with Salmonella serovar identical to the salmonellosis-affected child, no other Salmonella serovar but that identical to the child was isolated (Table 1).

In 15 of the 19 examined households, an identical serovar to that of the salmonellosis-affected child was found in at least one reptile. In six reptiles, the respective identical Salmonella serovar was isolated from the oral cavity and in two lizards from the stomach. In 17 reptiles with the same serovar as the child, Salmonella was detected in the cloaca, and in seven the skin swab sample was positive. The identical serovars found in the infected children as well as in the reptiles in the respective households belonged to the following subspecies: I (10), II (1), IIIa (1), IV(3) (details for individual reptiles and also non-identical serovars are presented in Table 1).

Bearded dragons (Pogona vitticeps) were the most common species kept in households with salmonellosis in children ( 13 of 19 households). Furthermore 16 of 19 of the examined bearded dragons carried an identical Salmonella serovar to the human isolate in the respective household. In corn snakes (Pantherophis guttatus), an identical serovar in the snake and the salmonellosis-affected child was found in three of five examined animals from two different households. Only one tortoise and one turtle were kept in households investigated in this study. These animals, with each an identical serovar to the salmonellosis-affected child, were respectively located in two households. Details are listed in Table 2.

In nine households, the isolates from the infected child and from the reptile had an identical PFGE profile (PFGE data not shown). In six households the human and reptile isolates presented related PFGE patterns (repeated PFGE, Figure 1). Details are also given in Table 1.

\section{Discussion}

During the fifteen months period of this study, $65 \%$ $(134 / 206)$ of all Salmonella infections in children detected at the NRC were not due to the serovars $S$. Typhimurium and S. Enteritidis, which are normally transmitted via food ingestion. It is therefore possible that other sources of infection than food, i.e. reptiles in households, could be of relevance. Nearly half (34/79) of the parents who were contacted and questioned, answered that reptiles were present in the respective households. Even though only limited information exists on the presence of reptiles in Germany in general, this percentage by far exceeds recent estimates that reptiles were only kept in $1.2 \%$ of all German households in 2010 [26]. This highlights that the presence of reptiles in households appears to coincide with the occurrence of salmonellosis due to exotic serovars in children. This assumption is also supported by a study in the US demonstrating that children with 
Patterns obtained by XbaI restriction and pulsed-field gel electrophoresis (PFGE) for isolates from children with 'ReptileExotic-Pet-Associated-Salmonellosis' (REPAS) $(n=6)$ and reptiles $(n=6)$ living in the same respective households

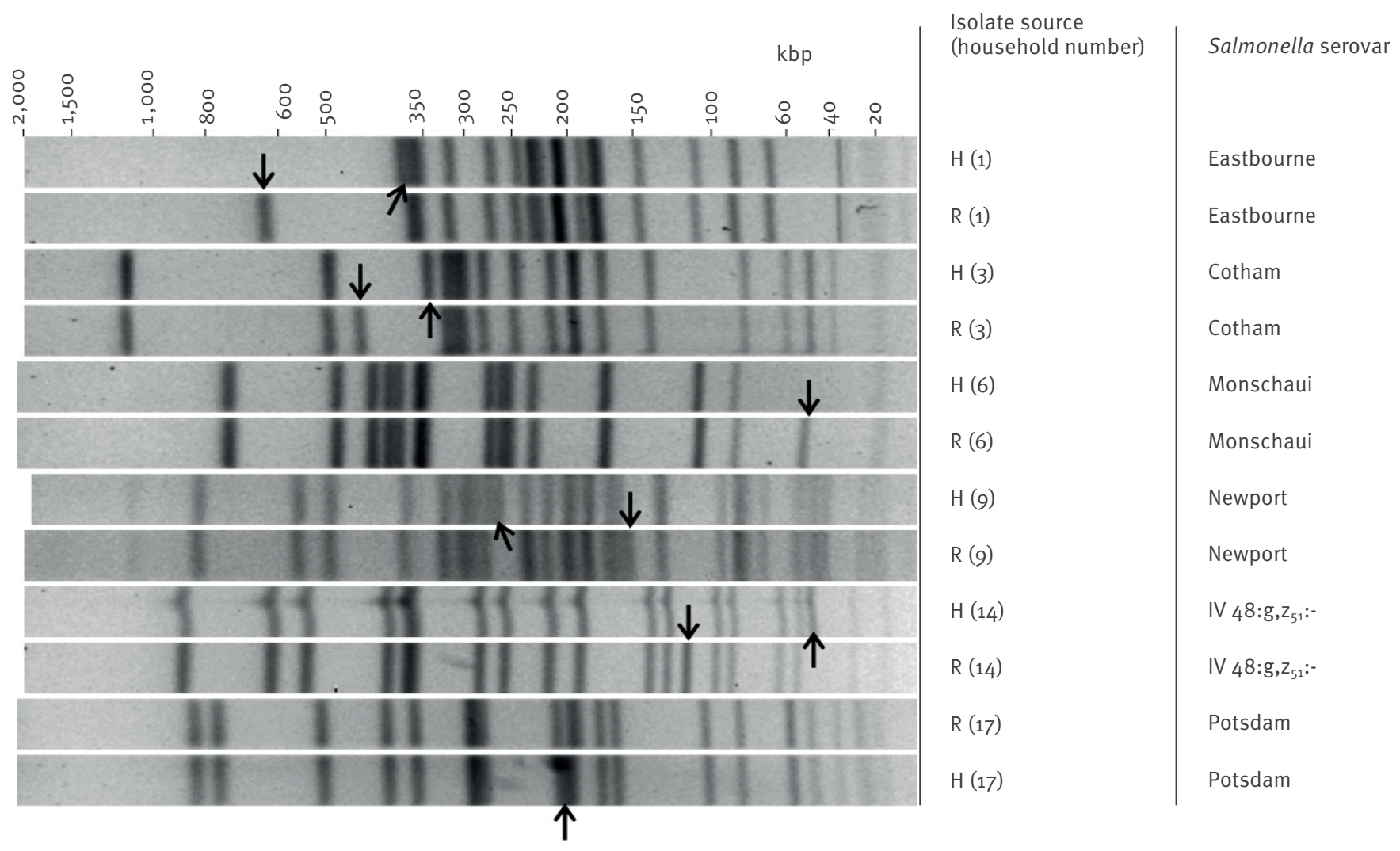

$\mathrm{H}$ : human isolate; $\mathrm{R}$ : reptile isolate.

Minor PFGE pattern differences between human and reptile isolates from the same households are shown and indicated by arrows.

confirmed Salmonella infections had more contact to reptiles and cats in comparison to a control group [27].

In most published case reports on RAS, only reptile faecal samples or faecal swabs were used for Salmonella detection. In contrast, this study was designed to obtain as much information as possible on Salmonella serovars shed by the reptiles. Sampling of the oral cavity (and stomach) as well as the cloaca should provide information on shedding via both orifices and if Salmonella are present within the whole digestive system, whereas sampling from the skin should demonstrate whether Salmonella may also be transmitted via direct contact with the animal. Repeated enrichment and culture was necessary to provide reliable information on the Salmonella status in the reptiles examined. Combining the molecular typing using PFGE with other available data, such as serological typing as in this study, is highly recommended for accurate analysis and comparison of samples [24].

The extensive sampling and testing protocol used in this study is a possible explanation for the high prevalence of Salmonella (in 35 of 36 reptiles) found among the reptiles investigated. Intermittent shedding of Salmonella in reptiles and the wide array of collection and sampling techniques have been proposed to be the main reason for the variability in detection rates [28]. None of the reptiles examined showed clinical signs indicative for salmonellosis. In consequence, a high prevalence of Salmonella in reptiles should generally be assumed, and reptiles should be considered positive for Salmonella until the contrary has been proven, as reported previously [29].

Up to four different serovars were found within one reptile. Reptiles were frequently colonised with the same serovars within a given household. This indicates that Salmonella as a part of the normal flora can spread amongst individuals within captive reptile collections and therefore probably shed over long periods of time. These results are in accordance with observations that if one reptile carries Salmonella, nearly all other reptiles of the respective owner are also affected [5].

Most Salmonella isolates were found in cloacal swabs. However, since in some reptiles the identical serovar to the salmonellosis-affected child was only found on 
the skin or the stomach, it can be assumed that shedding via the cloaca is intermittent. A negative cloacal or faecal sample will therefore not prove that the animal does not harbour Salmonella. Given the anatomy and behaviour of most reptiles, the presence of Salmonella on skin samples was not surprising but underlines the general transmission risk if handling the reptiles is not followed by appropriate hand washing. In conclusion, considering the various shedding sites, several sampling points should be used to increase the detection rate of Salmonella in reptiles.

In the majority (15/19) of the examined households, an identical serovar was found in the infected child and at least one reptile from the respective household. The epidemiological association between these isolates was first confirmed using biochemical typing. PFGE confirmed all reptiles, with either completely identical patterns (nine households) or only minor differences in up to two fragments indicating single genetic variations (six households, Figure 1), as described in disease outbreaks [24]. Most serovars found belonged to subspecies I and some have already been described as part of the reptile flora or even as potential human pathogens $[2,8,28]$. One serovar, $S$. Tennessee was isolated from four reptiles in three households. However, so far there seems to be no specific serovar that is of special zoonotic importance. In consequence, at the moment all Salmonella strains found in reptiles need to be considered to be potentially infectious for children.

An important finding of this study was that the reptile species involved could play an important role in transmission of Salmonella to children. Little data exists on the proportion of reptile species kept as pets in Germany. In a post-mortem survey, about $17 \%$ were water turtles, $34 \%$ tortoises, $22 \%$ snakes and $27 \%$ lizards (including $1.8 \%$ bearded dragons) [30]. In one of the authors' clinic specialising in reptile medicine, about $12 \%$ of more than 1,000 reptiles presented in the period of the running study were bearded dragons. However, in this study, the majority (13/19) of all households studied kept bearded dragons (Pogona vitticeps), and identical Salmonella strains to the salmonellosisaffected child were confirmed in 16 of 19 of these reptiles. In contrast, only one turtle and one tortoise were kept in the affected households studied. This result is in strong contrast to early reports of possible RAS in humans, where mainly turtles were suspected to be a source of infection. Interestingly, more recent case reports also indicate that bearded dragons present a risk for transmission of salmonellosis to young children [31,32].

Weiss et al. [12] reported a marked increase in infections in infants caused by $S$. Tennessee in Germany in 2008 and indicated the possibility of bearded dragons being a natural reservoir for this serovar, as this species was kept in seven of 16 households affected and $S$. Tennessee was confirmed in three households. Furthermore, probable transmission from bearded dragons has also recently been described in adult humans [33]. One explanation for the increasing number of reports on bearded dragons as a source of Salmonella infection in humans in recent years might be that this species is becoming more popular as a pet, and that bearded dragons are more often handled and petted due to their peaceful nature compared to several other reptile species. Since nearly all children included in this study were too young to handle reptiles themselves, it is likely that vectors, such as the parents or the environment may have played a role. Furthermore it is conceivable that bearded dragons naturally harbour a variety of potentially zoonotic Salmonella serovars. The fact that more than one serovar of Salmonella was isolated in 13 of a total of 19 bearded dragons supports this assumption.

Husbandry conditions and the households' hygiene status were not assessed according to a protocol, as this was not agreed upon with the owners. However, the overall impression was that most of the households visited demonstrated at least some deficits that needed corrections and advice, e.g. the reptile terrarium placed in the kitchen or in the same room as the child's bed. Further investigations in the environment of the reptile and possible interactions between the reptile and the persons in the households could give important information on possible transmission paths. None of the owners was aware of any risk of infection due to reptiles before, and all were therefore either willing to improve the situation or decided not to keep reptiles any longer.

All publications cited above indicate that although infections attributed to exposure to reptiles and other exotic pets represent only a small proportion of all human salmonellosis cases, it is likely an underestimated and growing problem in Europe [34] and in the US [35] that deserves closer attention. In 2007 more than 500,000 reptiles were imported to Germany only via the Frankfurt/Main airport [36]. According to the European Surveillance System (TESSy) database, the number of infections affecting children younger than three years with serovars associated to reptiles also increased in the last years (Figure 2). Beside the focus on exotic serovars as in this study, it should be kept in mind that there is also a potential risk for the transmission of $S$. Typhimurium and $S$. Enteriditis due to reptiles or as already described, via the reptile feed $[6,7]$. Also these common serotypes can be shedded by reptiles and therefore have a potential to cause salmonellosis in humans. For example, in this study $S$. Paratyphi B variant java was isolated from a corn snake. Although the identical serovar has not been found in the child from the respective household, this isolate belongs to phage type Worksop and is therefore of relevance for human infections.

From a terminological point of view, in addition to an earlier suggestion (RAS [37]), we propose that Salmonella infections related to reptiles as observed 
Occurrence of 'Reptile-Exotic-Pet-Associated-Salmonellosis' (REPAS) serovars in children less than three years-old in the European Union, 2007-2010

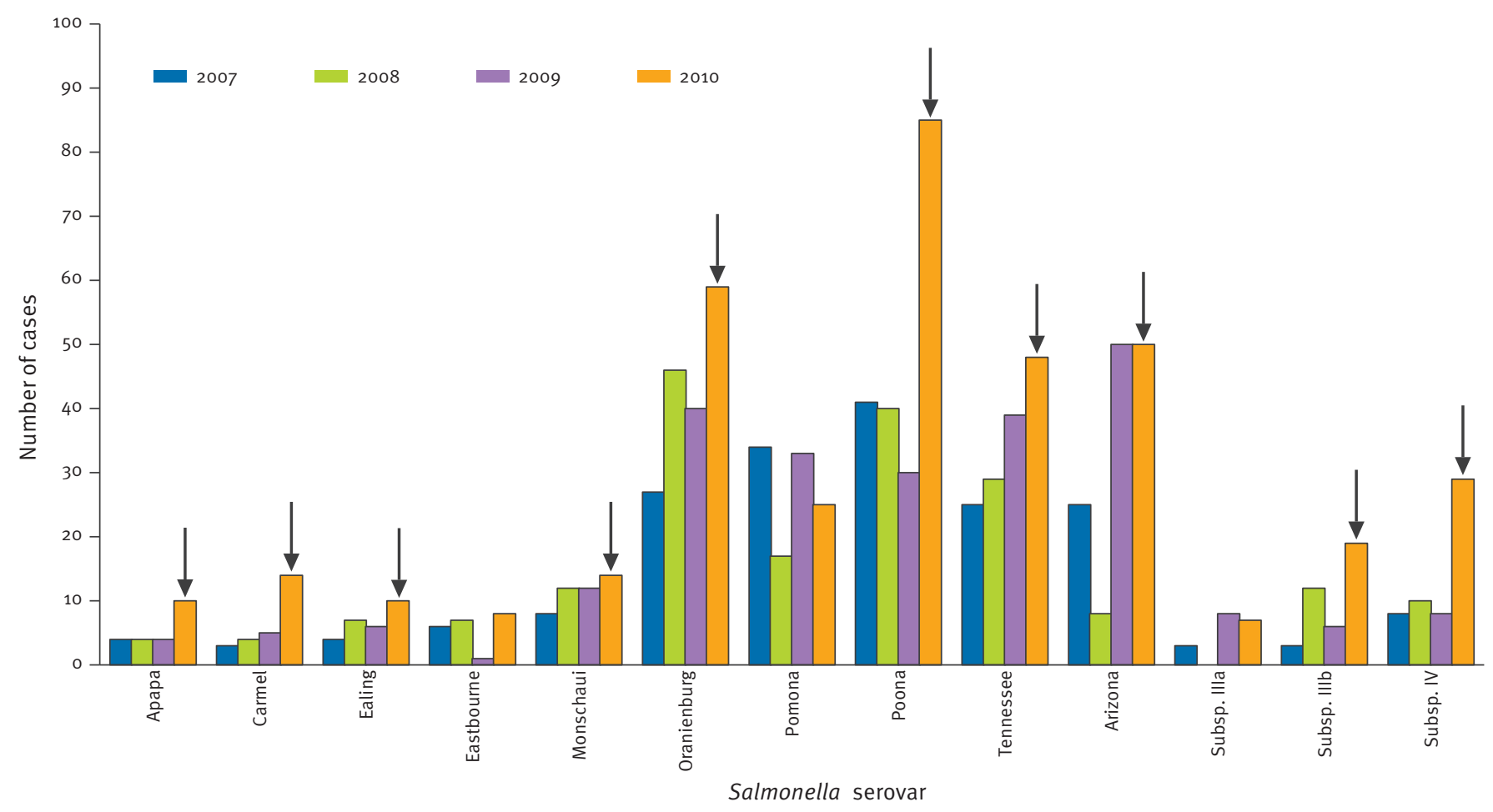

Salmonella Arizona includes subspecies IIla and subspecies IIIb. Arrows indicate where REPAS cases have increased in 2010 compared to previous years.

Data from the European Surveillance System (TESSy) (29 May 2012).

in this study be called 'Reptile-Exotic-Pet-AssociatedSalmonellosis' (REPAS) to give an indication of a possible source of exposure. The main argument for this proposal is that over the last years, the way of trading reptiles has changed considerably and this will probably continue in the future. The main risk of Salmonella transmission from reptiles to humans is not due to European wild species, but to 'exotic' (non-native) reptile species, as the results of this study also demonstrate. Furthermore, following recent examinations, Salmonella shedding is higher in reptiles kept in captivity in comparison to wild reptiles $[5,28]$ and 'pet' reptiles are obviously in closer contact to humans. These arguments justify the inclusion of 'exotic pet' into the term describing the problem. The risk to human health connected to the reptile pet market has been highlighted recently [38] and the accurate description of the problem using REPAS might be important to convey the problem in education and assist risk managers in giving recommendations to harmonise animal welfare and public health.

Concluding, emphasis on educational measures will be key to reduce the risk of Salmonella transmission from reptiles to children. Professionals dealing with reptiles (pet shop owners, veterinarians, breeders) should be aware of such a risk and, together with those dealing with human health, should be responsible to inform more about this problem. Given the fact that most owners in this study were unaware of the risk of Salmonella transmission from reptiles, we recommend that, in pet shops, any new exotic pet owner be provided with appropriate information sheets on Salmonella prevention. In the authors' opinion the risk of REPAS can easily be minimised, using a reasonable management protocol without the need to remove reptiles from households with young children.

\section{Acknowledgements}

The authors thank François-Xavier Weill, Centre for Reference and Research on Salmonella, Enteric Bacterial Pathogens Unit, Institut Pasteur, Paris, for the confirmation of the unusual S. Newport. We thank the Member States in the FWD network for submitting detailed serovar data, and Johanna Takkinen, European Center for Disease Prevention and Control (ECDC) for the European data. Furthermore, we thank Marita Wahnfried, Susanne Kulbe, Dagmar Busse for skillful technical assistance, and Rachel Marschang, University of Hohenheim, for linguistic support. 


\section{References}

1. Thomas AD, Forbes-Faulkner JC, Speare R, Murray C. Salmonellosis in wildlife from Queensland. J Wildl Dis. 2001;37(2):229-38.

http://dx.doi.org/10.7589/0090-3558-37.2.229

PMid:11310872

2. Woodward DL, Khakhria R, Johnson WM. Human salmonellosis associated with exotic pets. J. Clin Microbiol. 1997;35(11):278690.

PMid:9350734 PMCid:PMC230062

3. Pasmans F, Martel A, Boyen F, Vandekerchove D, Wybo I, Van Immerseel $F$, et al. Characterization of Salmonella isolates from captive lizards. Vet Microbiol. 2005;110(3-4):285-91. http://dx.doi.org/10.1016/j.vetmic.2005.07.008 PMid:16153787

4. Kikillus KH, Gartrell BD, Motion E. Prevalence of Salmonella spp., and serovars isolated from captive exotic reptiles in New Zealand. N Z Vet. J. 2011;59(4):174-8.

http://dx.doi.org/10.1080/00480169.2011.579246 PMid:21660846

5. Geue L, Löschner U. Salmonella enterica in reptiles of German and Austrian origin. Vet Microbiol. 2002;84 (1-2):79-91. http://dx.doi.org/10.1016/S0378-1135(01)00437-0

6. Harker KS, Lane C, De Pinna E, Adak GK. An outbreak of Salmonella Typhimurium DT191a associated with reptile feeder mice. Epidemiol Infect. 2011;139(8):1254-61. http://dx.doi.org/10.1017/S0950268810002281 PMid:20943001

7. Fuller CC, Jawahir SL, Leano FT, Bidol SA, Signs K, Davis C, et al. A multi-state Salmonella Typhimurium outbreak associated with frozen vacuum-packed rodents used to feed snakes. Zoonoses Public Health. 2008;55(8-10):481-7. PMid:18833597

8. Chiodini RJ, Sundberg JP. Salmonellosis in reptiles: a review. Am J Epidemiol. 1981;113(5): 494-9. PMid:7013476

9. Willis C, Wilson T, Greenwood M, Ward L. Pet reptiles associated with a case of salmonellosis in an infant were carrying multiple strains of Salmonella. J Clin Microbiol. 2002;40(12):4802-3.

http://dx.doi.org/10.1128/JCM.40.12.4802-4803.2002 PMid:12454202 PMCid:PMC154656

10. Center for Disease Control and Prevention (CDC). Reptileassociated salmonellosis - selected states, 1998-2002. MMWR Morb Mort Wkly Rep. 2003;52(49):1206-9. PMid:14668712

11. Kaibu H, lida K, Ueki S, Ehara H, Simasaki Y, Anzai H, et al. Salmonellosis of infants presumably originating from an infected turtle in Nagasaki, Japan. Jpn J Infect Dis. 2006;59(4):281. PMid:16936357

12. Weiss B, Rabsch W, Prager R, Tietze E, Koch J, Mutschmann F, et al. Babies and bearded dragons: sudden increase in reptileassociated Salmonella enterica serovar Tennessee infections, Germany 2008. Vector Borne Zoonotic Dis. 2011;11(9):1299301. http://dx.doi.org/10.1089/vbz.2010.0239 PMid:21612527

13. Hernández E, Rodriguez JL, Herrera-León S, García I, de Castro V, Muniozguren N. Salmonella Paratyphi B var Java infections associated with exposure to turtles in Bizkaia, Spain, September 2010 to October 2011. Euro Surveill. 2012;17(25): pii= 20201. Available from: http://www. eurosurveillance.org/ViewArticle.aspx?Articleld=20201 PMid:22748004

14. Warwick C, Lambiris AJ, Westwood D, Steedman C. Reptilerelated salmonellosis. J R Soc Med. 2001;94(3):124-6. PMid:11285792 PMCid:PMC1297927

15. Mermin J, Hutwagner L, Vugia D, Shallow S, Daily P, Bender J, et al. Reptiles, amphibians, and human Salmonella infection: a population-based, case-control study. Clin Infect Dis. 2004;38 Suppl 3:S253-61. http://dx.doi.org/10.1086/381594 PMid:15095197

16. Stam F, Römkens TE, Hekker TAM, Smulders YM. Turtleassociated human salmonellosis. Clin Infect Dis. 2003;37(11):e167-9. http://dx.doi.org/10.1086/379612 PMid:14614690

17. Baby dies of Salmonella poona infection linked to pet reptile. Commun Dis Rep CDR Wkly. 2000;10(18):161.

18. Wisconsin Division of Public Health (DPH). Disease fact sheet series: Reptile associated salmonellosis. Madison: Wisconsin Department of Health Services; 2004. P-42082.
19. Böhme H, Fruth A, Rabsch W. Reptilien-assoziierte Salmonelleninfektionen bei Säuglingen und Kleinkindern in Deutschland. [Reptile-associated Salmonellosis in Infants in Germany]. Klin Padiatr. 2009;221(2):60-4. German. http://dx.doi.org/10.1055/s-0028-1112156 PMid:19263324

20. Grimont PA, Weill FX. Antigenic formulae of the Salmonella serovars. Paris: WHO Collaborating Centre for Reference and Research on Salmonella, Institut Pasteur; 2007.

21. Ribot EM, Fair MA, Gautom R, Cameron DN, Hunter SB, Swaminathan B, et al. Standardization of pulsed-field gel electrophoresis protocols for the subtyping of Escherichia coli 0157:H7, Salmonella, and Shigella for PulseNet. Foodborne Pathog Dis. 2006;3(1):59-67. http://dx.doi.org/10.1089/fpd.2006.3.59 PMid:16602980

22. Van Belkum A, Tassios PT, Dijkshoorn L, Haeggman S, Cookson B, Fry NK, et al. Guidelines for the validation and application of typing methods for use in bacterial epidemiology. Clin Microbiol Infect. 2007;13 Supp 3:1-46. http://dx.doi.org/10.1111/j.1469-0691.2007.01786.x PMid:17716294

23. Goering RV. Pulsed field gel electrophoresis: A review of application and interpretation in the molecular epidemiology of infectious disease. Infect Genet Evol. 2010;10(7):866-75. http://dx.doi.org/10.1016/j.meegid.2010.07.023 PMid:20692376

24. Barrett TJ, Gerner-Smidt P, Swaminathan B. Interpretation of pulsed-field gel electrophoresis patterns in foodborne disease investigations and surveillance. Foodborne Pathog Dis. 2006;3(1):20-31. http://dx.doi.org/10.1089/fpd.2006.3.20 PMid:16602976

25. Sangal V, Harbottle H, Mazzoni CJ, Helmuth R, Guerra $\mathrm{B}$, Didelot $\mathrm{X}$, et al. Evolution and population structure of Salmonella enterica serovar Newport. J Bacteriol. 2010;92(24):6465-76.

http://dx.doi.org/10.1128/JB.00969-10 PMid:20935094 PMCid:PMC3008538

26. Statistica. Anteil der Haushalte in Deutschland mit Haustieren nach Tierarten in den Jahren 2008 bis 2012. Statistica. [Accessed 19 Sep 2012]. German. Available from: http:// de.statista.com/statistik/daten/studie/30153/umfrage/ haustiere-heimtierhaltung-in-deutschen-haushalten-seit-2008/

27. Younus M, Wilkins MJ, Davies HD, Rahbar MH, Funk J, Nguyen $C$, et al. The role of exposures to animals and other risk factors in sporadic, non-typhoidal Salmonella infections in Michigan children. Zoonoses Public Health. 2010;57(7-8):e170-6. http://dx.doi.org/10.1111/j.1863-2378.2010.01324.x PMid:20202185

28. Scheelings TF, Lightfoot D, Holz P. Prevalence of Salmonella in Australian reptiles. J Wildlife Dis. $2011 ; 47(1): 1-11$. http://dx.doi.org/10.7589/0090-3558-47.1.1 PMid:21269991

29. Pasmans F, Blahak S, Martel A, Pantchev N. Introducing reptiles into a captive collection: The role of the veterinarian. Vet J. 2008;175(1):53-68 http://dx.doi.org/10.1016/j.tvjl.2006.12.009 PMid:17346998

30. Sinn AD. Pathologie der Reptilien - eine retrospektive Studie [PhD thesis]. Munich: Ludwig-Maximilian-University; 2004. German.

31. Tabarani CM, Bennett NJ, Kiska DL, Riddell SW, Botash AS, Domachowske JB. Empyema of preexisting subdural hemorrhage caused by a rare Salmonella species after exposure to bearded dragons in a foster home. J Pediatr. 2010;156(2):322-3. http://dx.doi.org/10.1016/j.jpeds.2009.07.050 PMid:20105642

32. Haase R, Beier T, Bernstadt M, Merkel N, Bartnicki J. Neugeborenensepsis durch Salmonella Apapa nach Reptilienkontakt im Haushalt. [Neonatal infection with Salmonella apapa after contact with a reptile in the home]. $Z$. Geburtshilfe Neonatol. 2011; 215(2):86-8. German. http://dx.doi.org/10.1055/s-0031-1275308 PMid:21541908

33. Lowther SA, Medus C, Scheftel J, Leano F, Jawahir S, Smith K. Foodborne outbreak of Salmonella subspecies IV infections associated with contamination from bearded dragons. Zoonoses Public Health. 2011;58(8):560-6. http://dx.doi.org/10.1111/j.1863-2378.2011.01403.x PMid:21824356

34. Editorial team, Bertrand S, Rimhanen-Finne R, Weill FX, Rabsch W, Thornton L, et al. Salmonella infections associated with reptiles: The current situation in Europe. Euro Surveill. 2008;13(24):pii=18902. Available from: http://www. eurosurveillance.org/ViewArticle.aspx?Articleld=18902 
35. Center for Disease Control and Prevention (CDC). Notes from the field: outbreak of salmonellosis associated with pet turtle exposures - United States, 2011. MMWR Morb.Mort Wkly Rep. 2012;61(4):79.

PMid:22298304

36. Hatt JM, Fruth A, Rabsch W. Reptilienassoziierte Salmonellosen - aktuelle Informationen für Tierärztinnen und Tierärzte. [Reptile-associated salmonellosis -information update for veterinarians]. Tierärztliche Praxis. 2009;37(3):188-93. German.

37. De Jong B, Andersson Y, Ekdahl K. Effect of Regulation and Education on Reptile-associated Salmonellosis. Emerg Infect Dis. 2005;11(3):398-403

http://dx.doi.org/10.3201/eid1103.040694

PMid:15757554 PMCid:PMC3298264

38. Arena PC, Steedman C, Warwick C. Amphibian and reptile pet markets in the EU: An investigation and Assessment. Düsseldorf: Animal public e.V.; 2012. [Accessed 15 Dec 2012]. Available from: http://animal-public.de/wp-content/ uploads/2012/04/ARPM2012_V131.pdf 